\title{
Development of Sugarcane Bagasse Reinforced Onibode Clay Composite for Engineering Applications
}

\author{
${ }^{1}$ Joseph B. Agboola, ${ }^{2}$ Bolaji S. Hassan and ${ }^{1}$ Afeez A. Lukman \\ ${ }^{1}$ Department of Metallurgical and Materials Engineering, University of Lagos, Lagos, Nigeria \\ ${ }^{2}$ National Institute of Mining and Geosciences, Jos, Nigeria \\ \{joeagboola | profsbolajihassan | lukafeez\}@gmail.com
}

Received: 11-JUL-2020; Reviewed: 11-OCT-2020; Accepted: 20-SEP-2021

$\underline{\text { http://dx.doi.org/10.46792/fuoyejet.v6i3.548 }}$

\begin{abstract}
The quest to address the environmental pollution effect posed by agro-waste by way of turning them into useful materials for engineering applications is the motivation for this research work. In this study, sugarcane bagasse (SCB) reinforced Onibode clay composite was developed via slip casting technique. Clay samples from Onibode, Ogun state, Nigeria was collected at depth of 5 meters beneath the earth surface. Sugarcane bagasse was collected from a local market in Alaba-rago, Nigeria. Onibode clay-sugarcane bagasse composite samples were developed from a mixture of fine clay particles $(<150 \mu \mathrm{m})$ and SCB reinforcement particles (fine $-<150 \mu \mathrm{m} ;$ coarse $-300 \mu \mathrm{m}$ ) of $0-6 \%$ wt with a constant $53 \%$ wt moisture and five drops of sodium silicate. The samples were fired at a temperature of $1150{ }^{\circ} \mathrm{C}$ and held for 1 hour. Mechanical properties such as thermal conductivity, linear shrinkage, bulk density and apparent porosity of the samples were evaluated. The results show that $2 \mathrm{wt} \%$ sugarcane bagasse (SCB) reinforcement improved the mechanical properties of the developed composite.
\end{abstract}

Keywords- Clay, Insulator, Refractory properties, Sugarcane bagasse

\section{INTRODUCTION}

A gro-waste polymer composite has found its increasing significant in the building, construction and automobile industries because of their good mechanical properties such as high strength, high stiffness, good thermal insulation and good corrosion resistance (Hassan, et al., (2018). Some natural materials considered as waste can be used for manufacturing of new products with enhanced sustainable properties (Isiaka, 2014). The search for high-performance materials that do not impact negatively on the environment and health is going on all over the world. Presently, ceramic insulators are being replaced by composite insulators but the materials are deficient in mechanical strength and are costly (Apeh et al., 2015). In order to improve the mechanical property and reduce cost, silicon rubber is blended with ethylene vinyl acetate (EVA), but in doing so some reduction in hydrophobicity was observed (Ryan, 1978).

Various studies have been carried out on the development of biodegradable agro-based composites by using natural fibres as reinforcement (Fong et al.,2018). Previous use of sugar-cane bagasse was discussed by Agunsoye \& Aigbodion (2013). Sugarcane bagasse belongs to a class of agricultural wastes which their improper management could have negative impact on the environment (Aigbodion et al., 2010). However, their biodegradable nature makes them environmentally friendly. Their low-cost and high stiffness makes them suitable as reinforcing material for applications requiring high strength to weight ratio.

*Corresponding Author

Section D- MATERIALS/ CHEMICAL ENGINEERING \& RELATED SCIENCES Can be cited as:

Agboola, J.B., Hassan, S.B. and Lukman, A.A. (2021): Development of Sugarcane Bagasse Reinforced Onibode Clay Composite for Engineering Applications, FUOYE Journal of Engineering and Technology (FUOYEJET), 6(3), 52-55. http://dx.doi.org/10.46792/fuoyejet.v6i3.548
In developing countries like Nigeria which produces this waste in huge proportion, their usage in composite development would reduce their negative effect on the environment (Bello et al., 2015). Aigbodion et al. (2010) in their study characterised sugarcane bagasse to explore their potential utilisation in Metallurgical and Materials industry. It was concluded that the primary compounds in Carbonised sugarcane bagasse are Quartz $\left(\mathrm{SiO}_{2}\right)$, Cliftonite (C), Moissanite ( $\mathrm{SiC}$ ) and Titanium Oxide ( $\mathrm{Ti}_{6} \mathrm{O}$ ) and is thermally stable up to $100{ }^{\circ} \mathrm{C}$ and that sugarcane bagasse is suitable for the production of refractory membrane, filters and ceramic products for insulation. Fong, et al. (2018) compared the effects of different weightage of short fibre and fibre particulates of sugarcane bagasse on the mechanical properties of the sugarcane bagasse reinforced epoxy composite. Sugarcane bagasse particulates reinforced composites were shown to have better performance compared to short fibre reinforced composites when the wt $\%$ of the fibre increase.

Hassan et al. (2018) investigated the potential of incorporating Sugarcane bagasse and wheat straw into the production of insulating fired clay brick. Physical, mechanical and thermal properties of the bricks were tested. It was concluded that even though incorporating the wastes resulted into a decrease in the mechanical properties, the bricks still comply by the minimum standard for compressive strength. Phonphuak and Chindaprasirt (2018) investigated the effects of incorporating sugarcane bagasse ash (SCBA) on the properties of fired clay bricks. It was observed that the firing shrinkage values were slightly increased with increase in the SCBA content but were still within limit of the standard requirement. It was concluded that SCBA was a potential material for use as a pore-former additive to raw clay-brick production.

Potiron et al. (2010) has reported that adding retified bagasse fibres reduces composites thermal conductivity and yields a weaker specific heat in comparison with 
composites made with alkaline bagasse fibres. Moreover, the more the fibres, the lighter the specimen; lower its thermal conductivity and lower its specific heat. Isiaka (2014) used sugarcane bagasse (Saccharum officinarum) fibre to reinforce unsaturated polyester material in order to assess the viability of the composite materials developed for engineering applications. It was concluded that the mechanical properties of the developed composites were enhanced with a verge point value of 10 wt $\%$ reinforcement.

Omotoyinbo \& Oluwole (2008) investigated the working properties of the Ara-Awo-Isan clay deposits in Ekiti State with the view to propose other possible uses of the clays apart from the local pottery making for which the deposits are known. It was concluded that the clay samples contain aluminium oxide $\left(\mathrm{Al}_{2} \mathrm{O}_{3}\right)$ and silica $\left(\mathrm{SiO}_{2}\right)$ as major constituents making them suitable as aluminosilicate refractory materials. Proper disposal and general management of agro-wastes has remained a major challenge. There has been a huge gap to be filled in terms of the utilization by way of recycling through processing and conversion to useful materials.

The quest to address the environmental pollution effect posed by agro waste by way of turning them into useful materials for engineering applications is the motivation for this research work. Hence, this work is aimed at using sugarcane bagasse as reinforcement for developing low cost, environmentally friendly sugar cane bagasse reinforced Onibode clay composite for engineering applications.

\section{Materials and Methods}

\subsection{MATERIALS}

The materials used in this research are clay obtained from Onibode deposit (at a depth of five metres beneath the earth surface), Mile-7 along Ajebo Road, Abeokuta SouthWest, Ogun State, Nigeria and Sugarcane bagasse obtained from a local market at Alaba-rago, LagosBadagry Expressway, Lagos, Nigeria. Other materials used are plaster of paris (POP), tap water. Sodium silicate was used as deflocculant.

\subsection{Methods}

Sugarcane bagasse was soaked in tap water and decanted at two days' interval for eight days and later dried in the sun. The dried sugarcane bagasse was then ground and pulverised into particulate form which were graded into different sizes through sieving analysis. Onibode clay was crushed and soaked in water for three days; intermittently stirred and decanted to form slurry which was then allowed to settle for seven days. The resulting clay was sun dried for two days and grinded. A multipurpose pulveriser was used to reduce the clay further into finer particles.

The prepared clay was then mixed with a constant $53 \%$ wt water, and $0-2 \%$ wt $300 \mu \mathrm{m}$ particulate sugarcane bagasse at intervals of $2 \%$. Similarly, the clay was mixed with $53 \%$ wt water and fine sugarcane bagasse particles
$(150 \mu \mathrm{m})$ at intervals of $1 \%$. The slurry slip mixture was poured into the prepared POP moulds of the various test methods specifications shape. The slip mixture was allowed to settle for about 20 minutes, and the excess slip drained off. The samples were then removed and allowed to dry at room temperature.

The samples were sun dried for 2 days, and then dried in the electric oven at a temperature of $110^{\circ} \mathrm{C}$ for 12 hours to remove excess water through evaporation. The dried samples were then fired in an electric furnace to the vitrification temperature range of $1150^{\circ} \mathrm{C}$ and held at the temperature for one hour. The samples were then allowed to cool in the furnace. The quality of the produced samples was determined on the basis of refractory properties such as apparent porosity, linear shrinkage, bulk density and thermal conductivity. Apparent porosity of the produced samples was determined using equation (1) according to Atanda et al. (2012)

$$
P a=\frac{W_{B}-W_{A}}{W_{A}} \times 100(\%)
$$

where, $\mathrm{Pa}_{\mathrm{a}}=$ apparent porosity

$$
\begin{aligned}
& W_{A}=\text { dry weight } \\
& W_{B}=\text { soaked weight }
\end{aligned}
$$

Drying and firing shrinkage was calculated using equations 2 and 3

$$
\begin{aligned}
& \text { \%Dry shrinkage }=\frac{\left(L_{w}-L_{d}\right)}{L_{d}} \times 100(\%) \\
& \% \text { Fired shrinkage }=\frac{\left(L_{d}-L_{f}\right)}{L_{f}} \times 100(\%) \\
& \text { Where: } L_{w}=\text { wet length } \\
& L_{f}=\text { fired length } \\
& L_{d}=\text { dry length }
\end{aligned}
$$

Bulk density of the samples was calculated using equation (4) according to Atanda et al.,2012.

$$
\text { Bulk density }=\frac{D}{W-S} D w
$$

Where $D=$ weight of dried specimen

$$
\begin{aligned}
& D_{w}=\text { Density of water } \\
& S=\text { weight of suspended specimen } \\
& W=\text { weight of soaked specimen }
\end{aligned}
$$

Boiling method was used in determining the thermal conductivity of the samples. The thermal conductivity of the test samples was determined using the expression in equation (5) according to Sekunowo et al (2017).

$$
\lambda=\frac{2.303 m c \delta \log \frac{T_{S}-T_{1}}{T_{S}-T_{2}}}{A t}
$$

where, $\lambda=$ thermal conductivity of the sample $(\mathrm{W} / \mathrm{mk})$

$\delta=$ thickness of the sample $(\mathrm{m})$

Ts $=$ temperature of steam $\left({ }^{\circ} \mathrm{C}\right)$

$\mathrm{T}_{1}=$ initial temperature of water in conical flask $\left({ }^{\circ} \mathrm{C}\right)$

$\mathrm{T}_{2}=$ final temperature of water in conical flask $\left({ }^{\circ} \mathrm{C}\right)$

$\mathrm{t}=$ time $(\mathrm{s})$

$A=$ sample area $\left(\mathrm{m}^{2}\right)$

$\mathrm{m}=$ mass of water in conical flask $(\mathrm{kg})$

$\mathrm{c}=$ specific heat capacity of water in conical flask $\left(\mathrm{J} / \mathrm{kg}{ }^{\circ} \mathrm{C}\right)$ 
Table 1. Experimental Design

\begin{tabular}{|c|c|c|c|c|}
\hline \multirow[b]{2}{*}{ Sample Identification } & \multirow[b]{2}{*}{$\begin{array}{c}\text { Moisture } \\
\text { (\% wt) }\end{array}$} & \multirow[b]{2}{*}{$\begin{array}{l}\text { Onibode Clay } \\
\text { (\% wt) }\end{array}$} & \multicolumn{2}{|c|}{ Sugarcane Bagasse $(\% \mathrm{wt})$} \\
\hline & & & $\begin{array}{l}\text { Coarse } \\
(300 \mu \mathrm{m})\end{array}$ & $\begin{array}{c}\text { Fine } \\
(150 \mu \mathrm{m})\end{array}$ \\
\hline Control (Cs) & 53 & 47 & - & - \\
\hline D1 & 53 & 46 & - & 1 \\
\hline A1 & 53 & 45 & - & 2 \\
\hline E1 & 53 & 44 & - & 3 \\
\hline B1 & 53 & 43 & - & 4 \\
\hline $\mathrm{F} 1$ & 53 & 42 & - & 5 \\
\hline $\mathrm{C} 1$ & 53 & 41 & - & 6 \\
\hline
\end{tabular}

\section{RESULTS AND DISCUSSION}

\subsection{INFLUENCE OF PARTICLE SIZE OF SGB}

Introduction of SGB particles into the composite mixture showed a progressive decrease in the flowability (workability) of the slip. This is due to the absorbent nature of the SGB particles. Only $2 \%$ wt of the coarsely dispersed SGB particles (300 microns) produced sample with good formability (sample A). This further shows that there is a limit to the volume fraction of reinforcement which could be used in a composite design.

Figure 1 shows the percentage linear shrinkage of the samples. The linear shrinkage of the samples was obtained in terms of the dry shrinkage, fired shrinkage, and the total shrinkage

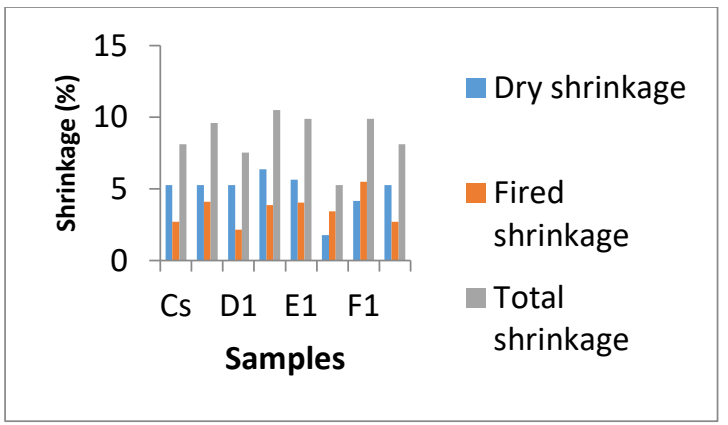

Fig. 1: Linear shrinkage of samples

From Figure 1, sample B1 has the least total shrinkage of $5.26 \%$, while samples A1, E1, and F1 possess higher total shrinkage of $10.50 \%, 9.89 \%$, and $9.89 \%$ respectively. These values are within the range for alumino-silicate clay (Ryan, 1978). However, the higher shrinkage values obtained for most samples are likely to be responsible for the cracks observed on the surfaces of the samples after firing. The firing shrinkage of the samples is a significant parameter as it gives a measure of the efficiency of moisture removal (Hassan, 2005). All samples possess a firing shrinkage of between $2.15 \%$ to $5.49 \%$.

The apparent porosity of the composite samples is shown in Figure 2. The apparent porosity of all samples is found to be between 20 and $40 \%$ which is within the normal values for insulating bricks (Ryan, 1978). The high value of apparent porosity shows that the SGB reinforcement were fully burnt off and left adequate pores within the structure of the composite.

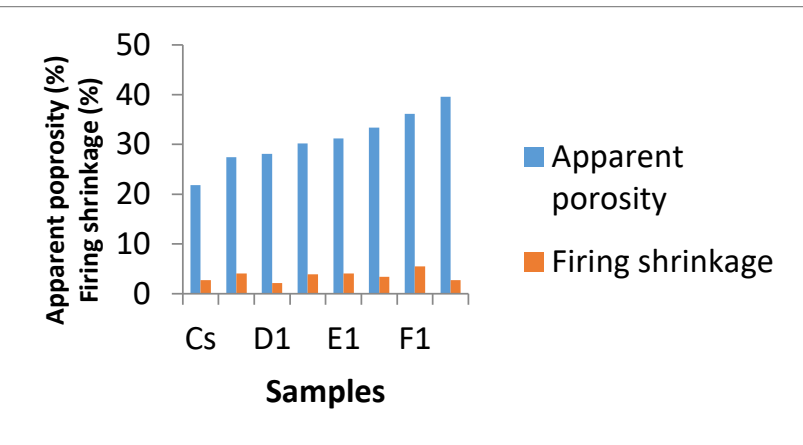

Fig. 2: Apparent porosity and firing shrinkage of the samples

Figure 3 shows the bulk density of the samples. The bulk densities are found to be between 1.59 and $1.90 \mathrm{~g} / \mathrm{cm}^{3}$. Samples Cs, A, and E1 are within the acceptable range of 1.7 to $2.1 \mathrm{~g} / \mathrm{cm}^{3}$ for porcelain wares (Ryan, 1978); while the other samples have values less than this range. The bulk density gives a measure of the firing efficiency.

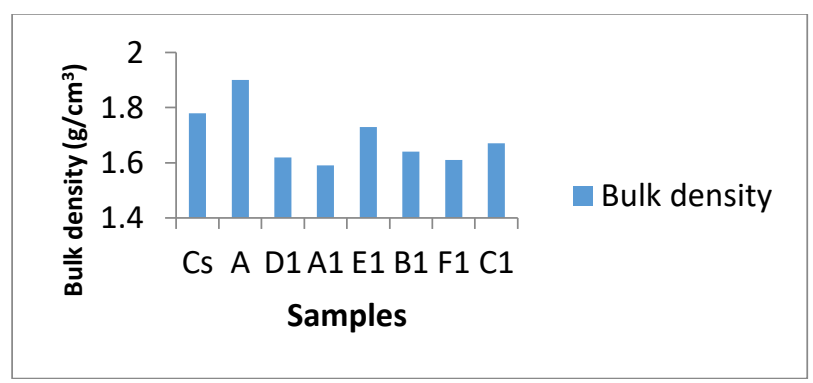

Fig. 3: Bulk density of all samples

Figure 4 shows that thermal conductivity of the developed composite was between 0.0078 and 0.0254 $\mathrm{W} / \mathrm{mK}$. The thermal conductivity of a material depends on the intrinsic conductivity of the material of which it is made and the porosity. Thermal conductivity decreases as porosity increases in agreement with (Hassan, 2005).

Table 2 shows the summary of mechanical properties of the developed Sugarcane bagasse reinforced Onibode clay composite (SCBC). 
Table 2. Mechanical properties of the developed Sugarcane bagasse reinforced Onibode clay composite (SCBC)

\begin{tabular}{ccccc}
\hline & $\begin{array}{c}\text { Thermal } \\
\text { conductivity (W/Mk) }\end{array}$ & Linear Shrinkage (\%) & $\begin{array}{c}\text { Bulk density } \\
\left(\mathbf{g} / \mathbf{c m}^{3}\right)\end{array}$ & Apparent Porosity (\%) \\
\hline SCBC & 0.0254 & 4.03 & 1.59 & 20 \\
Standard values & 0.27 & 4.20 & 1.74 & 7.05 \\
\hline
\end{tabular}

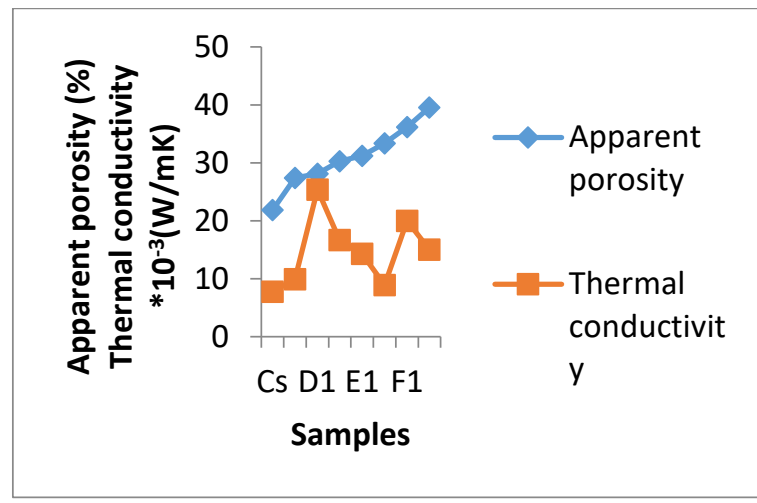

Fig. 4: Thermal conductivity and porosity

\section{Conclusions}

Sugar cane bagasse reinforced composite was successfully produced from Onibode clay. Based on the outcome of the research, one of the conclusions that can be drawn is that Sugarcane bagasse (SCB) waste in the range of $2 \%$ wt. can be used as reinforcement for Onibode clay for the development of environmentally friendly composite material suitable for engineering application. Also, the use of Sugar cane bagasse as reinforcement for Onibode clay significantly improved the mechanical properties of the developed composite with optimum firing shrinkage value of $4.03 \%$, apparent porosity of $31.22 \%$, bulk density of $1.73 \mathrm{~g} / \mathrm{cm}^{3}$, and thermal conductivity of $0.0143 \mathrm{~W} / \mathrm{Mk}$. Lastly, the optimum moisture content required to form a slip casting of Sugarcane bagasse (SCB) reinforced Onibode clay composite is $53 \% w t$, with addition of five drops of sodium silicate.

\section{REFERENCES}

Acharya, S., Mishra, P. P., \& Mehar, S. K. (2009). The influence of fibre treatment on the performance of bagasse fibre-reinforced polymer composite. Journal of Reinforced Plastics and Composites, 28(24), 3027-12.

Agunsoye, J. O., \& Aigbodion, V. S. (2013). Bagasse filled recycled polyethylene bio-composites: Morphological and mechanical properties study. Results in Physics, 3, 187-194.

Aigbodion, V. S., Hassan, S. B., \& Agunsoye, J. O. (2012). Effect of bagasse ash reinforcement on dry sliding wear behaviour of polymer matrix composites. Materials \& Design, 33, 322-327.

Aigbodion, V. S., Hassan, S. B., Nyior, G. B., \& Ause, T. (2010). Effect of Bagasse ash reinforcement on the wear behaviour of $\mathrm{Al}-\mathrm{Cu}-$ $\mathrm{Mg} /$ Bagasse ash particulate composites. Acta Metall. Sin. (Engl. Lett.), 23(2), 81-89.

Apeh, F. I., Esezobor, D. E., Lawal, G. I., Adeosun, S. O., \& Agunsoye, J. M. (2013). The Effect of Temperature Difference on the Thermal Shock Behavior of Onibode Fire-Clay Material with the Addition of Alumina. The International Journal of Engineering and Science, 2(9), 84-87
Bello, S. A., Agunsoye, J. O., Hassan, S. B., Zebase Kana, M. G., \& Raheem, I. A. (2015). Epoxy Resin Based Composites, Mechanical and Tribological Properties: A Review. Tribology in Industry, 37(4), 500-524.

Fong, A.L. Khandoker, N.A.N. and Debnath, S. (2018), Development and characterization of sugarcane bagasse fibre and Nano-silica reinforced epoxy hybrid composites, IOP Conference Series: Materials Science and Engineering, 344.

Hassan, S. B. (2005). Modern Refractories; Production, Properties, Testing, and Applications. Zaria.

Hassan, A.M. Abadir, M.F. and Moselhy, H. (2018), Use of Agricultural Waste in the Preparation of Insulating Fireclay Bricks; International Journal of Applied Engineering Research, 13, (12), 10819-10825

Isiaka O. O. (2014); Effect of Bagasse Fibre Reinforcement on the Mechanical Properties of Polyester Composites; The Journal of the Association of Professional Engineers of Trinidad and Tobago ;42(1), 12-15

Kadir, A. and N. Maasom. (2013). "Recycling sugarcane bagasse waste into fired clay brick." International Journal of Zero Waste Generation, 1(1), 21-26.

Omotoyinbo, J. A., \& Oluwole, O. O. (2008). Working Properties of Some Selected Refractory Clay Deposits in South Western Nigeria. Journal of Minerals \& Materials Characterization \& Engineering, 77(33), 233-245.

Phonphuak, N. and Chindaprasirt, P. (2018); Utilization of sugarcane bagasse ash to improve properties of fired clay brick; Journal of Science 45(4):1855-1862

Potiron, C.O. Coutrin, N.P., Toro, F. Delvasto, S. Bilba, K.;(2010); Sugar cane bagasse fibres reinforced cement composites: Thermal considerations. Applied Science and Manufacturing, Elsevier, 41 (4), 549-556. 